Provided for non-commercial research and education use. Not for reproduction, distribution or commercial use.

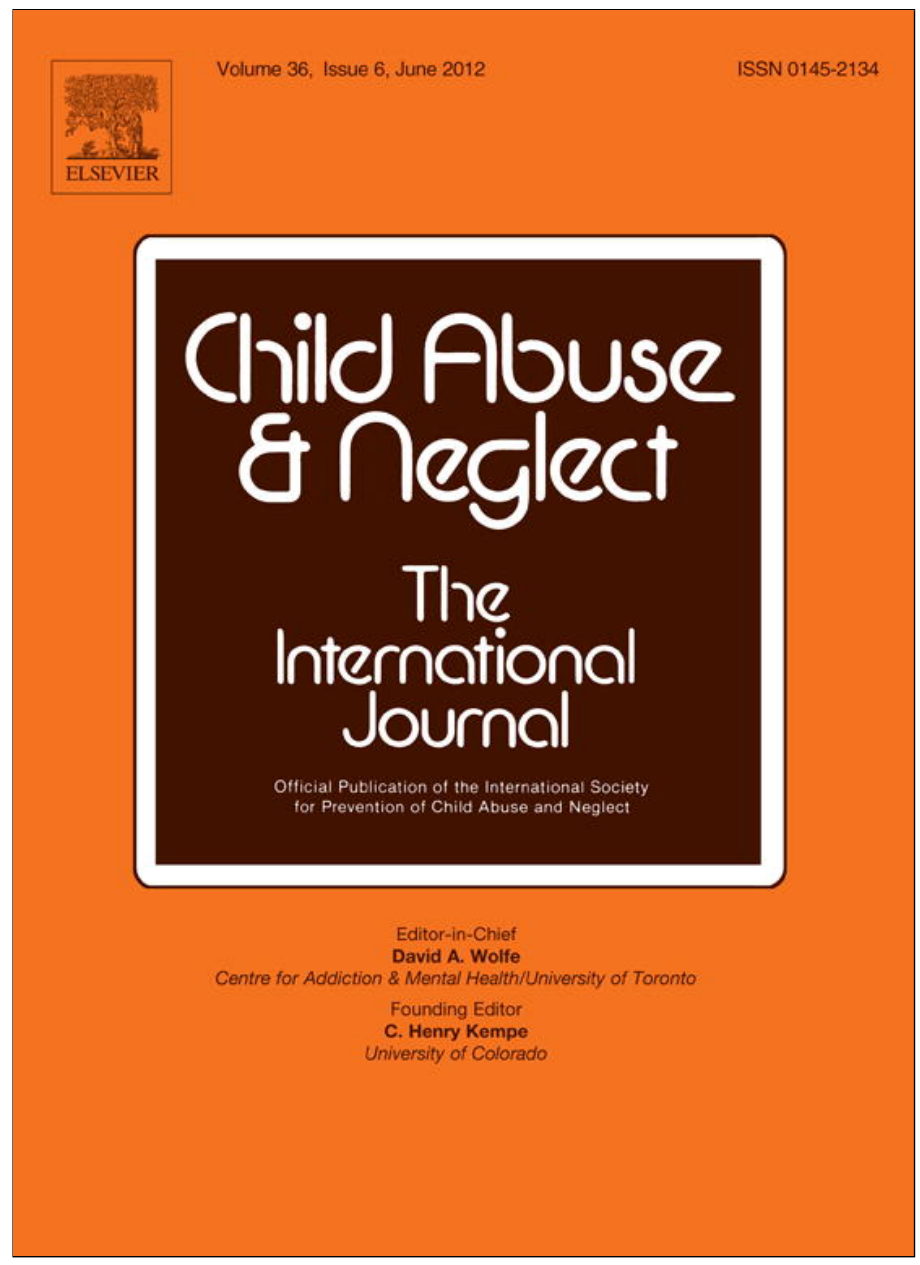

This article appeared in a journal published by Elsevier. The attached copy is furnished to the author for internal non-commercial research and education use, including for instruction at the authors institution and sharing with colleagues.

Other uses, including reproduction and distribution, or selling or licensing copies, or posting to personal, institutional or third party websites are prohibited.

In most cases authors are permitted to post their version of the article (e.g. in Word or Tex form) to their personal website or institutional repository. Authors requiring further information regarding Elsevier's archiving and manuscript policies are encouraged to visit:

http://www.elsevier.com/copyright 


\title{
Parental agreement of reporting parent to child aggression using the Conflict Tactics Scales ${ }^{\text {i⿱ }}$
}

\author{
Shawna J. Lee ${ }^{\mathrm{a}, *}$, Jennifer E. Lansford ${ }^{\mathrm{b}}$, Gregory S. Pettit ${ }^{\mathrm{c}}$, John E. Bates ${ }^{\mathrm{d}}$, Kenneth A. Dodge ${ }^{\mathrm{e}}$ \\ a School of Social Work and Research Center for Group Dynamics, University of Michigan, Ann Arbor, MI, USA \\ b Center for Child and Family Policy, Duke University, Durham, NC, USA \\ c Department of Human Development and Family Studies, Auburn University, Auburn, AL, USA \\ d Department of Psychological and Brain Sciences, Indiana University, Bloomington, IN, USA \\ e Sanford School of Public Policy; and Department of Psychology and Neuroscience, Duke University, Durham, NC, USA
}

\section{A R T I C L E I N F O}

\section{Article history:}

Received 4 January 2012

Received in revised form 21 April 2012

Accepted 25 April 2012

Available online 2 July 2012

\section{Keywords:}

Child Development Project

Mother

Father

Self-report

Validity

Reliability

Generalizability

Parent to Child Conflict Tactics Scale

CTSPC

Child abuse

\begin{abstract}
A B S T R A C T
Objectives: This study examined mothers' and fathers' reporting congruency using the Parent-Child Conflict Tactics Scales. We asked if the mother's report of the father's parenting aggression was consistent with the father's self-report of parenting aggression and if the father's report of the mother's parenting aggression was consistent with the mother's selfreport of those same behaviors. We assessed moderators of parental reporting congruency: severity of the aggression, interparental conflict, child temperament, and child gender. Methods: Participants were from the Child Development Project, a longitudinal study beginning when children were in kindergarten. The analyses herein included 163 children for whom 2 parents provided data about their own and their spouse or partner's behavior toward the child. Most parents (87\%) were married. Mothers and fathers independently completed the Parent-Child Conflict Tactics Scale, both with respect to their own behavior toward the child and with respect to their partner's behavior toward the child. Mothers completed the retrospective Infant Characteristics Questionnaire to assess child temperament. Mothers and fathers completed measures of interparental conflict.

Results: Both fathers and mothers self-reported more frequently engaging in each behavior than the other parent reported they did. Parents were more congruent on items assessing harsher parenting behavior. Furthermore, there was more agreement between parents regarding fathers' behavior than mothers' behavior. Analyses of interparental conflict, child difficult temperament, and child gender as moderators yielded findings suggesting that mothers' and fathers' reports of their own and their spouses' harsh parenting behaviors were more concordant in couples with low levels of conflict, for children with easy temperaments, and for boys versus girls.

Conclusions: Prior studies indicate only a moderate level of agreement in couples' reports of violence between intimate partners and suggest that perpetrators tend to underreport their use of aggression. The results of this study suggest that parents may be more consistent in their reports of parent to child violence using the Parent-Child Conflict Tactics Scales than they are when reporting intimate partner violence. The results suggest that parental reports of their spouse's parent to child aggression are reliable.
\end{abstract}

(c) 2012 Elsevier Ltd. All rights reserved.

\footnotetext{
is The Child Development Project has been funded by grants MH42498, MH56961, MH57024, and MH57095 from the National Institute of Mental Health, HD30572 from the Eunice Kennedy Shriver National Institute of Child Health and Human Development, and DA016903 from the National Institute on Drug Abuse. Kenneth A. Dodge is supported by Senior Scientist award 2K05 DA015226 from the National Institute on Drug Abuse. This work also was supported by grant 0818478 from the National Science Foundation.

* Corresponding author address: University of Michigan, School of Social Work, 1080 South University Avenue, Ann Arbor, MI 48109, USA.
} 


\section{Introduction}

An often-discussed topic in the study of family violence is how to accurately and reliably measure aggression that occurs in the home and may be hidden from others. Both researchers and clinicians frequently rely on parental self-report of parent to child aggression. However, the inherently intimate nature of acts of aggression that occur within the family raises numerous questions regarding the validity and reliability of measures that are obtained via self-report. Further complicating matters is that there is no gold standard against which to calibrate the validity of self-report of parent to child aggression (Vega \& O'Leary, 2007). Most alternatives to parental self-report, such as Child Protective Services (CPS) reports or selfreport of the child, have their own limitations and caveats and may be even less reliable and valid than parental self-report measures.

The Parent-Child Conflict Tactics Scale (CTSPC) is a widely used self-report measure of parent to child aggression (Straus, 1979; Straus, Hamby, Finkelhor, Moore, \& Runyan, 1998). The CTSPC asks parents to recall and report both the incidence and frequency of a range of specific parenting behaviors, including nonviolent discipline (e.g., explained why something was wrong), physical aggression (e.g., spanked on bottom with bare hand; hit on the bottom, with a belt, a hairbrush, a stick, or some other hard object), and psychological aggression (e.g., shouted, yelled, or screamed) (Straus, 1979; Straus et al., 1998). Behaviors such as shaking a child or hitting a child hard enough to leave bruises would constitute child maltreatment by most definitions, and would warrant CPS investigation. Other behaviors, such as spanking on the bottom with a bare hand, are known to increase risk for physical child abuse, but do not necessarily constitute child abuse according to most state laws (Gershoff, 2002; Straus, 2001; Straus \& Hamby, 1997; Straus et al., 1998).

One advantage of the CTSPC is that the use of standardized self-report instruments allows for comparability across multiple studies (Schafer, 1996). Furthermore, the CTSPC has been normed with nationally representative US samples allowing for population-level comparisons (Straus et al., 1998; Straus \& Stewart, 1999; Straus \& Field, 2003) and is also used to measure the incidence of parent to child aggression worldwide in the UNICEF Multiple Indicator Cluster Survey (MICS). However, social desirability may also result in underreport in the incidence of parental aggression against children (Straus \& Hamby, 1997). In addition, parents may not easily recall commonly used forms of parental discipline, such as spanking or explaining to a child what he or she did was wrong, and thus parents may underestimate their frequency of engaging in these behaviors (Straus \& Hamby, 1997; Straus et al., 1998). Even with these concerns, the CTSPC has established construct and content validity and, as noted above, is used worldwide to measure the prevalence of caregiver aggression toward children.

Although numerous studies underscore the validity of the CTSPC as a measure of parent to child aggression, questions remain regarding the generalizability of parental reports, particularly when one parent (most often, the mother) is called upon in a research study to report the behavior of the other parent or another caregiver of the child. Although it would be preferable to assess potential bias by collecting data from multiple reporters, in most studies the expense and logistics of collecting data from multiple reporters is prohibitive. In general, there are relatively few child maltreatment studies that collect data directly from caregivers besides the child's mother.

As a result, maternal report of fathers' parent to child aggression is common (e.g., Lee, Guterman, \& Lee, 2008; Lee, Altschul, Shair, \& Taylor, 2011). Yet, prior research has not examined whether mothers or fathers are reliable and unbiased reporters of their spouse or partner's use of parent to child aggression or whether maternal reports of fathers' behaviors can be generalized. One possibility is that mothers may systematically report that their spouse or partner engages in more parent to child aggression than the spouse or partner self-reports, perhaps because there are fewer social desirability biases in reporting about someone else's behavior. In addition, if the relationship between the parents is poor, over-reporting may reflect a perception of the partner as a "bad parent;" it is also possible that parents who have poor relationship quality are less likely to observe each other as co-parents and therefore will have less accurate information about the spouse or partner's behavior toward the child.

One way to assess the reliability of a research instrument is to examine agreement among raters-that is, the extent to which reporters are congruent in their responses (Schafer, 1996). The current study examined mothers' and fathers' reporting congruency using the CTSPC. Specifically, we asked if the mother's report of the father's parenting aggression was consistent with the father's self-report of parenting aggression and if the father's report of the mother's parenting aggression was consistent with the mother's self-report of those same behaviors. We also examined several potential moderators of parental reporting congruency: severity of the parent to child aggression, child temperament, interparental conflict, and child gender.

\section{Congruency of reporting partner violence}

Issues regarding the reliability of reports from multiple sources have been examined in the partner violence literature. In general, when examining reports from men and women in couples, studies indicate CTS inter-partner correlations ranging from $r=.32$ to $r=.59$ (Vega \& O'Leary, 2007), suggesting a moderate level of agreement in couples' reports of partner violence. Studies have shown that discrepancies between partners often take the form of underreporting by the perpetrator (Edelson \& Brygger, 1986; Vega \& O'Leary, 2007), and that both men and women report a lower level of aggression for themselves than their partners attributed to them (Archer, 1999) 
and a greater discrepancy in partner-self reports for husbands when compared to wives (Simpson \& Christensen, 2005).

However, the most common model of parent to child aggression is one in which both parents are the perpetrators of punishment toward the child (Taylor, Lee, Guterman, \& Rice, 2010). Furthermore, even though fathers spend less time caring for children than mothers do, mothers and fathers do not greatly differ in their use of some of the common parenting behaviors measured by the CTSPC, such as spanking (Straus \& Stewart, 1999). Therefore, it is unclear whether the processes observed in the partner violence literature, where perpetrators underreport their level of aggression due to self-presentational biases, can be applied to parental reports of parent to child aggression. Specifically, given that both parents are approximately equally likely to perpetrate parent to child aggression (e.g., spanking), it is unclear whether parents or their partners may self-report lower levels of parent to child aggression. It seems equally plausible that parents could over-report or under-report parent to child aggression for one's spouse or partner, perhaps due to lack of full information regarding that person's actual behavior or for other reasons, such as high levels of interparental conflict.

An additional consideration is the influence of parental gender. Even in dual parent families, mothers spend more time caring for and monitoring their children than do fathers (Yeung, Sandberg, Davis-Kean, \& Hofferth, 2001), and therefore mothers are more likely than fathers to have direct knowledge about the child (Crouter, Helms-Erikson, Updegraff, \& McHale, 2003). Thus, mothers are more likely to have direct knowledge of the child's behavior, as well as greater knowledge of the father's interaction with the child. In contrast, fathers spend less time caring for and monitoring children, and are less likely to spend time caring for children outside of the mother's direct observation (Yeung et al., 2001). As a result, mothers may have a greater degree of consistency in their reports of fathers' parent to child aggression, whereas fathers may have less direct knowledge of how the mother parents the child and therefore may have less agreement in their evaluation of the mothers' behaviors vis-à-vis maternal self-report.

One factor that may influence the ability of parents to accurately recall and report their partner's behavior is the nature of the event itself. In a study of partner violence, both husbands and wives showed greater agreement when asked about behaviors that were more objective and specific (Simpson \& Christensen, 2005). More severe forms of conflict may be less frequent and more memorable, and thus more readily incorporated into a dyadic view of the relationship, facilitating subsequent recall of more extreme acts, such as the use of physical aggression (Straus, 1979).

\section{Potential moderators of parental congruency of CTSPC reports}

Difficult child temperament: There is evidence that children with a more difficult temperament elicit more parental involvement and experience more punishment from their parents, with some indication that this link is stronger for boys than for girls (Blackson, Tarter, \& Mezzich, 1996; McBride, Schoppe, \& Rane, 2002; Weiss, Dodge, Bates, \& Pettit, 1992). Children whom parents perceive as having a more challenging temperament may require more parental discussion of the child and higher levels of parental coordination to address child behavior problems (Bates, Schermerhorn, \& Goodnight, 2010; Cook, Schoppe-Sullivan, Buckley, \& Davis, 2009). As such, child temperament may serve as a moderator of parental congruency in reports of parent to child aggression. If parents engage in relatively more discipline of children with difficult temperaments as compared to those with easy temperaments, such discipline events may be less memorable to parents and also more likely to occur outside the direct observation of the co-parent.

Interparental conflict: There is reason to believe that parents' reports of their partner's behavior sensitive to the interparental relationship. For example, maternal and paternal reports of father involvement with the child may be influenced by the quality of the interparental relationship (Coley \& Morris, 2002; Mikelson, 2008). In one study, when fathers did not reside in the home, mothers and fathers were more likely to be discrepant in their reports of the level of father involvement with the child (Mikelson, 2008); father's residency status did not influence reports of father involvement in another study (Coley \& Morris, 2002).

Although the mechanisms that would contribute to discrepant parental reports of father involvement are unclear, it is possible that parents who have higher levels of interparental conflict spend less time actively co-parenting, which may include fewer opportunities to observe their spouse or partner in the parenting role and fewer discussions of their use of discipline toward the child. Therefore, parents in high conflict relationships may have fewer opportunities to learn of and observe their spouse or partner's behavior toward the child. In the current study, all parents were married or cohabiting. We examined the extent to which interparental verbal and physical conflict would moderate parental congruency in reporting parent to child aggression.

Child gender: Research suggests that in two-parent families, fathers may be more involved in caring for male as compared to female children whereas no gender preferences are observed in maternal caregiving behaviors (Mammen, 2011; Yeung et al., 2001). Although the disparity in fathers' involvement and parenting of boy versus girl children may be waning over time (Raley \& Bianchi, 2006) and may be moderated by factors such as sibling constellation (Mammen, 2011), it is possible that if fathers spend more time with boys they may also be more involved in disciplining male children. As such, parents may be more consistent when reporting on their aggression toward boys than toward girls. Therefore, in this study we also examine whether gender of the child may serve as a moderator of parental consistency in reporting parent to child aggression. 
The goal of this study was to examine parental congruency in reports of parent to child aggression. We used mothers' and fathers' reports of their behavior toward the child, as well as their reports of their spouse or partner's behavior toward the child, to examine several competing hypotheses previously not examined using the CTSPC. One hypothesis is that individuals are biased reporters of their partner's behavior. If this hypothesis is correct, we would most likely find that each member of the dyad reports significantly higher or lower levels of aggression for their partner than their partner self-reports; and that mothers' and fathers' reports are significantly discrepant from each other.

A competing hypothesis is that mothers and fathers are generally congruent when comparing self-reports of behavior to partner reports. In this case, the mother's report of the father's aggression toward the child will be consistent with the father's self-report of aggression toward the child; and the father's report of the mother's aggression toward the child will be consistent with the mother's self-report of aggression toward the child. Of course, a parent may not be totally accurate when reporting their partner's behavior because they lack full information on that person's interactions with the child. This hypothesis addresses whether there is reason to believe that there is systematic bias in reporting of a spouse or partner's parent to child aggression when compared to self-report by the spouse or partner. We expect to find congruency in parental reports, with self-reports similar to partner's report. Furthermore, consistent with prior research showing that mothers engage in more discipline of children, we would expect to find that mothers self-report slightly more aggression for themselves than fathers self-report. This hypothesis does not rule out the possibility of self-report biases that exist with any measure that asks individuals questions of a sensitive nature. Rather, evidence in support of this hypothesis will indicate whether a spouse or partner, most likely, the wife or mother, can be relied upon to accurately recall and report their partner's behavior in a manner that is consistent with what the partner would have reported had they been asked the same questions.

We also examined a series of other possible influences and moderators. First, we expected that the behavior being assessed would influence parental recall of the partner's behavior. We hypothesized that parents would have a higher level of congruency on items that assessed harsh parenting behaviors, such as physical aggression (Straus, 1979). Second, because mothers are generally more involved in caring for their children than fathers are, and fathers tend to rely more on information from mothers in the parenting process, we expected to find that mothers' reports of fathers' behaviors would be more congruent with fathers' self-reports than vice versa. Third, we hypothesized that children with difficult temperaments would have parents who were less congruent in their reports of parent to child aggression than would children with easier temperaments. Fourth, we hypothesized that parents with higher levels of interparental conflict would have less knowledge of their partner's behavior and therefore these parents would be less congruent in reporting parent to child aggression. Fifth, we hypothesized that parents may be more consistent when reporting on boys' aggression than reporting on girls' aggression.

\section{Method}

\section{Participants}

Participants for this study were recruited in 1988 from Nashville and Knoxville, TN and Bloomington, IN for the Child Development Project (Dodge, Bates, \& Pettit, 1990), a multi-site, longitudinal study. Parents were approached at random and were asked to participate at the time of their child's kindergarten preregistration or, for those parents who did not preregister, were contacted by letter during the first weeks of the kindergarten school year. Approximately $75 \%$ of parents approached agreed to participate in the study, for a total of 273 families (those in cohort 2 of the larger project).

The analyses in the present study include the 163 children for whom 2 parents provided data about their own and their spouse or partner's behavior toward the child. Eighty-seven percent of these dyads included biological parents of the child who were married, $<1 \%$ included biological parents of the child who were cohabiting, $10 \%$ included the biological mother and a stepfather who were married, $2 \%$ included the biological father and a stepmother who were married, and $<1 \%$ included the biological father and a stepmother who were cohabiting. Of these 163 children, $6 \%$ were African American, 92\% were European American, and 2\% were of other ethnic origin. Fifty-four percent of the target children were female. Family SES was determined based on the Hollingshead's (1979) Four-Factor Index ( $M=39.71, S D=13.78)$. Compared to the sample that did not have data available from 2 parents, the sample with data from 2 parents was more likely to be European American, $\chi^{2}(2)=38.83, p<.001$, and more likely to have a female child, $\chi^{2}(1)=6.58, p<.05$, but did not differ by family SES, $t(243)=-1.51, n s$.

\section{Procedure and measures}

Institutional review boards at the participating universities approved the procedures, and parents provided written informed consent. Parents received modest financial compensation for their time. During the summer before children started kindergarten or during the fall of the kindergarten school year, mothers and fathers (or mother and father figures in the household) completed in-home interviews that included the following measures.

Parent behavior toward child. Mothers and fathers independently completed the Conflict Tactics Scale (Straus, 1979), both with respect to their own behavior toward the child and with respect to their spouse or partner's behavior toward the child. 
Table 1

Means, standard deviations, and paired t-tests comparing mothers' and fathers' reports of the frequency of fathers' behavior.

\begin{tabular}{|c|c|c|c|}
\hline & Mother report $M(\mathrm{SD})$ & Father report $M(\mathrm{SD})$ & $t$ \\
\hline Tried to discuss calmly & $4.14(1.79)$ & $4.10(1.67)$ & -.11 \\
\hline Did discuss calmly & $4.12(1.78)$ & $4.04(1.56)$ & -.50 \\
\hline Got information to back up side & $1.96(1.94)$ & $2.09(1.74)$ & .73 \\
\hline Brought in someone to help & $.85(1.53)$ & $.83(1.30)$ & -.12 \\
\hline Argued heatedly & $1.97(1.79)$ & $1.91(1.69)$ & -.29 \\
\hline Yelled & 1.45 (1.69) & $1.39(1.67)$ & -.37 \\
\hline Sulked & $.53(1.11)$ & $.55(1.00)$ & .18 \\
\hline Threw, smashed, or kicked something & $.33(.80)$ & $.31(.59)$ & -.18 \\
\hline Threatened to throw something at child & $.09(.46)$ & $.05(.48)$ & -.82 \\
\hline Threw something at child & $.04(.30)$ & $.01(.08)$ & -1.51 \\
\hline Pushed, grabbed, or shoved child & $.46(.94)$ & $.63(1.11)$ & 1.68 \\
\hline Threatened to spank & $2.64(1.80)$ & $3.14(1.76)$ & $3.64^{* * *}$ \\
\hline Spanked & $2.01(1.67)$ & $2.10(1.54)$ & .81 \\
\hline Spanked with something & $.73(1.38)$ & $.85(1.36)$ & 1.01 \\
\hline Threatened to hit & $.29(1.05)$ & $.25(.85)$ & -.56 \\
\hline Hit or tried to hit with something & $.06(.32)$ & $.04(.33)$ & -.69 \\
\hline Threatened to beat up & $.01(.08)$ & $.06(.51)$ & 1.63 \\
\hline Beat up & $.00(.00)$ & $.00(.00)$ & $\mathrm{N} / \mathrm{A}$ \\
\hline
\end{tabular}

${ }^{*} p<.05,{ }^{* *} p<.01$.

$p<.001$.

Each parent completed ratings about behavior during the past year (corresponding to child age 4-5 years). Each item was rated on a 7 -point scale $(0=$ never, $6=$ almost every day). Consistent with scale construction in previous research (Straus, 1979, 2004; Straus et al., 1998), we averaged items (see Table 1) to construct scales reflecting 4 types of behaviors toward children: 1 . Discussion ( 4 items, $\alpha=.72, .71, .67$, and .75 for father report of own behavior, father report of mother's behavior, mother report of own behavior, and mother report of father's behavior, respectively); 2 . Verbal-aversive ( 2 items, $\alpha=.62$, $.62, .61$, and .67 for father report of own behavior, father report of mother's behavior, mother report of own behavior, and mother report of father's behavior, respectively); 3. Hostile-indirect ( 3 items, $\alpha=.63, .64, .73$, and .81 for father report of own behavior, father report of mother's behavior, mother report of own behavior, and mother report of father's behavior, respectively); 4. Aggression (11 items, $\alpha=.68, .71, .71$, and .74 for father report of own behavior, father report of mother's behavior, mother report of own behavior, and mother report of father's behavior, respectively).

Child difficult temperament. Mothers completed the retrospective Infant Characteristics Questionnaire (Bates \& Bayles, 1984; Bates, Freeland, \& Lounsbury, 1979), a retrospective account of the child's temperament during infancy that has been found to have validity in relation to early accounts (Bates, Pettit, Dodge, \& Ridge, 1998). Mothers were asked to rate items such as "Compared to other babies, how much did your baby usually cry and fuss?" and "How easily did your baby get upset?" on 7-point scales with the low anchors reflecting a very easy temperament (e.g., baby did not get upset even by things that would upset most babies) and the high anchors reflect a very difficult baby (e.g., easily upset by things that would not bother most babies). From this measure, we derived a scale reflecting child difficult temperament by averaging 9 items $(\alpha=.86)$.

Interparental conflict. Interparental conflict was assessed using items from the Conflict Tactics Scale (Straus, 1979). Mothers were asked to recall 2 eras in the child's life (age 1 to age 4 and age 4 to age 5 ) and to rate separately for each era the conflict tactics that they used toward their spouse and that their spouse used toward them. Each of 28 items ( 7 for mother behavior toward father in each of 2 eras and 7 for father behavior toward mother in each of 2 eras) was rated on a 6-point scale ranging from 0 (never) to 6 (almost every day). Items included verbal aggression (e.g., yelled, insulted or swore), hostile-indirect behaviors (e.g., stomped out of the room or house), and physical aggression (e.g., pushed, grabbed, or shoved). The scores were averaged to create an interparental conflict composite variable $(\alpha=.94)$.

\section{Results}

We first examined correlations between father and mother reports of fathers' behavior and between father and mother reports of mothers' behavior. Father and mother reports of fathers' behavior were correlated $.19, p<.05 ; .29, p<.001 ; .21$, $p<.01$; and $.60, p<.001$ for fathers' discussion, verbal-aversive, hostile-indirect, and aggression, respectively. Father and mother reports of mothers' behavior were correlated .28, $p<.001 ; .24, p<.01 ; .12, p>.10$; and .39, $p<.001$ for mothers' discussion, verbal-aversive, hostile-indirect, and aggression, respectively. Fischer's $r$ to $z$ transformations were used to compare whether pairs of correlations were significantly different from one another. For reports of fathers' behavior, the mother-father correlation for fathers' aggression was significantly larger than the mother-father correlation for fathers' discussion, verbal-aversive, or hostile-indirect; the latter three scales did not differ significantly from one another. For reports of mothers' behavior, the mother-father correlation for mothers' aggression was significantly larger than the mother-father correlation for mothers' hostile-indirect; none of the other scale pairs significantly differed from one another. Mother-father 
Table 2

Means, standard deviations, and paired t-tests comparing mothers' and fathers' reports of the frequency of mothers' behavior.

\begin{tabular}{|c|c|c|c|}
\hline & Mother report $M(\mathrm{SD})$ & Father report $M(\mathrm{SD})$ & $t$ \\
\hline Tried to discuss calmly & $4.73(1.55)$ & $4.22(1.68)$ & $3.36^{* * *}$ \\
\hline Did discuss calmly & $4.67(1.44)$ & $4.23(1.45)$ & $3.44^{* * *}$ \\
\hline Got information to back up side & $2.60(1.93)$ & $2.04(1.72)$ & $2.72^{* *}$ \\
\hline Brought in someone to help & $1.10(1.68)$ & $1.10(1.52)$ & -.04 \\
\hline Argued heatedly & $2.17(1.76)$ & $2.31(1.69)$ & -.84 \\
\hline Yelled & $1.96(1.90)$ & $1.69(1.84)$ & 1.40 \\
\hline Sulked & $.58(.99)$ & $.57(1.05)$ & -.12 \\
\hline Threw, smashed, or kicked something & $.27(.71)$ & $.15(.46)$ & 1.89 \\
\hline Threatened to throw something at child & $.05(.29)$ & $.08(.45)$ & -.73 \\
\hline Threw something at child & $.04(.23)$ & $.04(.40)$ & .17 \\
\hline Pushed, grabbed, or shoved child & $.64(1.05)$ & $.67(1.19)$ & -.27 \\
\hline Threatened to spank & $3.33(1.77)$ & $3.17(1.88)$ & 1.20 \\
\hline Spanked & $2.51(1.59)$ & $2.27(1.56)$ & $2.16^{*}$ \\
\hline Spanked with something & $.93(1.44)$ & $.89(1.47)$ & .37 \\
\hline Threatened to hit & $.55(1.31)$ & $.18(.68)$ & $3.23^{* *}$ \\
\hline Hit or tried to hit with something & $.07(.34)$ & $.02(.14)$ & 1.80 \\
\hline Threatened to beat up & $.02(.14)$ & $.00(.00)$ & 1.74 \\
\hline Beat up & $.00(.00)$ & $.00(.00)$ & $\mathrm{N} / \mathrm{A}$ \\
\hline
\end{tabular}

${ }^{*} p<.05$.

${ }^{* *} p<.01$.

${ }^{* * *} \quad p<.001$.

agreement was significantly stronger for reports of fathers' aggression than for mothers' aggression; mother-father agreement did not differ significantly for the other three scales. Overall, these findings support the hypothesis that there would be more agreement between parents on whether each parent engaged in harsher parenting behavior and more agreement between parents regarding fathers' behavior than mothers' behavior.

Paired samples $t$-tests were then used to compare father's report of his own behavior with mother's report of the father's behavior and mother's report of her own behavior with father's report of the mother's behavior for each individual item. There was a significant difference in means for only 1 of the 20 comparisons between father's report of his own behavior with mother's report of the father's behavior (Table 1); fathers reported that they threatened to spank more frequently than mothers reported that fathers threatened to spank. There was a significant difference in means for 6 of the 20 comparisons between mother's report of her own behavior with father's report of the mother's behavior (Table 2); for all 6 items, mothers reported that they engaged in each behavior more frequently than fathers reported that mothers engaged in the behavior. These findings suggest that neither mothers nor fathers systematically over-reported the other parent's aggressive parenting. Instead, both fathers and mothers reported more frequently engaging in each behavior than the other parent reported they did, perhaps because fathers and mothers are more knowledgeable about all of the times that they engage in a particular behavior, which their partners may not have full awareness of if they are not present when the behavior occurs (see Table 3 ).

\section{Moderation by temperament, interparental conflict, and child gender}

We next turned to the question of whether child difficult temperament, interparental conflict, or child gender moderated the strength of the relation between mother-father agreement on fathers' and mothers' behavior. To address this question,

Table 3

Regression results predicting self report of a given behavior from spouse/partner report of that behavior from models with significant interaction terms.

\begin{tabular}{|c|c|c|c|c|c|}
\hline Predictor Variable & $B$ & SE $B$ & $\beta$ & $F$ & $R^{2}$ \\
\hline Regression 1 & & & & $6.37^{* * *}$ & .11 \\
\hline Father's report of mother's discussion & .27 & .08 & $.27^{* *}$ & & \\
\hline Difficult temperament & .06 & .11 & .05 & & \\
\hline Interaction & -.19 & .10 & $-.15^{*}$ & & \\
\hline Regression 2 & & & & $39.76^{* * *}$ & .43 \\
\hline Mother's report of father's aggression & .65 & .06 & $.73^{* * *}$ & & \\
\hline Interparental conflict & -.11 & .05 & $-.15^{*}$ & & \\
\hline Interaction & -.25 & .09 & $-.18^{* *}$ & & \\
\hline Regression 3 & & & & $4.92^{* *}$ & .09 \\
\hline Father's report of mother's verbal-aversive & .26 & .08 & $.25^{* *}$ & & \\
\hline Gender & -.21 & .24 & -.07 & & \\
\hline Interaction & -.33 & .16 & $-.16^{*}$ & & \\
\hline
\end{tabular}

${ }^{*} p<.05$.

** $p<.01$.

${ }^{* * *} p<.001$. 
we regressed fathers' reports of their own behavior on mothers' reports of fathers' behavior, the main effect of one of the moderator variables (child difficult temperament, interparental conflict, or child gender), and the interaction between mothers' reports of fathers' behavior and the moderator. Similarly, to predict mothers' reports of their own behavior, we calculated regressions using fathers' reports of mothers' behavior, the main effect of a moderator variable, and the interaction between fathers' reports of mothers' behavior and the moderator. This resulted in 8 regressions for each moderator (with the 4 behavior scales separately for mothers and fathers). To interpret significant interactions, we computed simple slopes at high (1 SD above the mean), medium (at the mean), and low (1 SD below the mean) levels of the continuous moderators (Aiken \& West, 1991; Jose, 2008).

Using child difficult temperament as the moderator, the interaction term was significant in 1 of the 8 regressions: The relation between fathers' reports of mothers' discussion and mothers' reports of their own discussion was weaker for children with difficult temperaments than for children with easy temperaments (slopes $=.11, .27$, and .43 at high, medium, and low levels of difficult temperament, respectively). Using interparental conflict as the moderator, the interaction term also was significant in 1 of the 8 regressions: The correlation between mothers' reports of fathers' aggression and fathers' reports of their own aggression was stronger between parents with low interparental conflict than for parents with high interparental conflict (slopes $=.51, .66$, and .82 at high, medium, and low levels of interparental conflict, respectively). Using child gender as the moderator, the interaction was significant in 1 of the 8 regressions: The correlation between fathers' reports of mothers' verbal-aversive behavior and mothers' reports of their own verbal-aversive behavior was stronger for boys $(r=.42, p<.001)$ than girls $(r=.09, n s)$.

\section{Discussion}

Issues of measurement reliability, validity, and generalizability are central to the study of family violence and child maltreatment. The CTSPC is a standardized measure that provides national data on parent to child aggression. It continues to be widely used in large survey studies of family violence, such as the UNICEF MICS, National Survey of Child and Adolescent Well-being, and the Fragile Families and Child Wellbeing Study. The CTSPC is used in part because there is strong evidence of its construct and content validity. For example, CTSPC content validity is high because it assesses a range of behaviors that include normative parental discipline (e.g., calm discussion) to more extreme behaviors that indicate child maltreatment (e.g., shaking a child, hitting a child with an object). Given its widespread use, it is paramount to understand issues of reliability in administering the CTSPC.

This study addressed an issue not previously examined in the literature, namely whether mothers and fathers, the majority of whom were married biological parents of the study target child, are reliable as reporters of their spouse or partner's disciplinary behaviors toward the child. We assessed the congruence of dyadic reports of items from the CTSPC measuring child discipline, including forms of non-aggressive discipline, physical aggression, and verbal aggression. Our analysis compared maternal self-report of these behaviors to father report of mothers' behavior and paternal self-report versus maternal report of fathers' behavior.

In general, parents were highly consistent in reports of discipline toward the child. Neither mothers nor fathers systematically over-reported the other parent's use of discipline. Instead, in the few instances in which there were discrepancies between mothers' and fathers' reports, both fathers and mothers self-reported more frequently engaging in each behavior than the other parent reported they did. This finding is consistent with our initial hypothesis that, if parental reports of their spouse or partner's behavior are generalizable, discrepancy would take the form of underreporting by the spouse or partner compared to self-report. Slight underreporting by partners is expected, given that fathers and mothers have full information of all of the times that they engage in a particular behavior, and their partners may not be aware of some behaviors that occur when they are not present.

Our first hypothesis that parents would have a higher level of congruency on items that assessed harsh parenting behaviors was confirmed by results that indicated significantly higher mother-father correlations on scales measuring more extreme behaviors, such as hostile-indirect behavior. Second, mothers tended to be more reliable in reporting on fathers' behaviors than vice versa. This is consistent with our hypothesis that mothers will have more accurate information regarding all instances of discipline directed toward the child, in part because mothers spend more time than fathers caring for children, particularly when children are young (Yeung et al., 2001). This finding is also consistent with prior research of parental monitoring and supervision that indicates that fathers get more of their information about the child from mothers, whereas mothers have direct information via their interactions with the child (Crouter, Bumpus, Davis, \& McHale, 2005; Updegraff, McHale, Crouter, \& Kupanoff, 2001).

Third, as hypothesized, we found that child temperament and interparental conflict moderated mother-father reporting congruency. Parents' reports of their own and their spouses' harsh parenting behaviors were more congruent when the child had an easy temperament, as rated by the child's mother. Children who are "difficult" to care for may require higher levels of parental engagement; therefore, parents may engage more frequently in discipline and therefore be less likely to recall specific instances of discipline and also have less direct knowledge of their partners' disciplinary behaviors. Interparental conflict also moderated reporting congruency. Couples with low levels of conflict were more consistent, suggesting that in better quality relationships, couples may also utilize co-parenting strategies in which they learn of, discuss, and observe their spouse or partner's behavior toward the child (McBride et al., 2002). 
Finally, as expected, child gender was also a significant moderator in our analyses. Mothers and fathers were more consistent in reporting of their verbal-aversive behavior for boys compared to girls. Our findings that parents are more congruent in reporting behaviors towards boys than girls may be explained by prior research indicating that fathers spend more time engaged in play with male children, and take on more direct childcare responsibilities with sons (Mammen, 2011). As such, they may be more involved in and have greater awareness of their partners' discipline of male children versus female children.

\section{Implications}

Prior studies using the CTS indicate only moderate level of agreement in couples' reports of partner violence and suggest that perpetrators tend to underreport their use of aggression (Archer, 1999; Edelson \& Brygger, 1986; Vega \& O'Leary, 2007). The results of this study suggest that parents may be more consistent in their reports of parent to child violence using the CTSPC than they are when reporting partner violence using the CTS. This may be explained in part by the different nature of the acts involved. The items in the CTSPC assess disciplinary behaviors, such as yelling and spanking, widely used by American mothers and fathers (Straus \& Stewart, 1999; Taylor, Lee et al., 2010; Taylor, Manganello, Lee, \& Rice, 2010). Therefore, partners may not perceive reporting on their (or their partner's) use of these behaviors to be quite as stigmatizing as partner violence.

The results of this study suggest that the CTSPC is a reliable self-report instrument to measure parent to child aggression and that parental reports of their spouse or partner's behavior can be generalized. In particular, maternal reports of fathers' behaviors are highly consistent with his self-report. An implication is that researchers can have confidence in the findings reported in prior research, in which mothers reported on fathers' parent to child aggression (e.g., Lee et al., 2008, 2011). There are practical considerations as well. To minimize self-report bias, it is ideal to triangulate self-report data and consider reports from multiple reporters; however, it is often not feasible to collect data from multiple sources, particularly when children are young. Future researchers may gain a better perspective on the extent of parent to child aggression in American families by asking about both mothers' and fathers' disciplinary behaviors, even when there is only one reporter in a household reporting on both parents' behaviors.

The results of this study support the continued use of the CTSPC as a valid, reliable, and generalizable instrument in research on family violence. Researchers choose to use measures such as the CTSPC because self-report data may be more valid and capture more instances of maltreating behaviors than are indicated by other measures (Straus \& Hamby, 1997). For example, CPS records are beset by numerous concerns regarding their accuracy. They are believed to greatly underestimate the actual number of children who are maltreated and are often inaccurate in classifying the type of abuse experienced by the child (Runyan et al., 2005). Furthermore, there is considerable state-to-state variation in definitions of child maltreatment and practices in identifying potentially abusive families. Another limitation of CPS records is that it can be difficult for researchers to collect administrative records and then link those records to parent and child characteristics, which is often the goal of research studies. Standardized measures such as the CTSPC provide an alternative to administrative data, in that they rely on the parent to indicate their use of aggression toward the child. While parents may underestimate their use of parent to child aggression, particularly for more serious forms of aggression, the CTSPC tool nonetheless captures a better sense of the range and variability in discipline exercised by parents of children than is possible relying solely on CPS maltreatment records.

\section{Study limitations}

It is important to note limitations of this study. The sample for this study consisted mostly of married parents who were biologically related to the target child. Thus, results may not generalize to other family configurations, such as step-parent families or families in which caregivers are not related to the child. An important caveat is that the parents in this study were living together and presumably had opportunities to observe their partners' parenting behaviors. As such, results cannot be generalized to maternal reports of fathers' behaviors (or vice versa) when the parents in question are not living together and therefore do not have consistent information on the other parent's behavior toward the child.

The results of this study do not indicate that the CTSPC is free from the biases that exist with all self-report measures. For example, it is quite plausible that both parents may underestimate their use of aggression to discipline their child. Additionally, this study does not address other limitations of the CTSPC. For example, the authors of the scale acknowledge that asking parents to recall the frequency of behaviors that are common, such as yelling and spanking, likely contributes to errors in recall (Straus \& Hamby, 1997). However, the results of this study do indicate that parents are likely to be systematic in the extent to which these factors influence their self-report as well as their report of their partner's behavior.

\section{Study conclusions}

Prior studies indicate only a moderate level of agreement in couples' reports of intimate partner violence and suggest that perpetrators tend to underreport their use of aggression (Arias \& Beach, 1987; Vega \& O'Leary, 2007). The results of this study suggest that parents may be more consistent in their reports of parent to child violence using the CTSPC than they are when reporting violence between intimate partners. Specifically, neither mothers nor fathers systematically over-reported 
the other parent's aggressive parenting. Instead, for the few behaviors that showed discrepancies in reporting, both fathers and mothers self-reported more frequently engaging in each behavior than the other parent reported they did. Parents were more congruent on items assessing harsher parenting behavior. There was more agreement between parents regarding fathers' behavior than mothers' behavior. Findings supported the hypothesis that mothers' and fathers' reports of their own and their spouses' harsh parenting behaviors were more concordant in couples with low levels of conflict but less concordant for children with difficult temperaments. In sum, the results of this study suggest that the CTSPC is a reliable measure of parent to child aggression, whether the measure is administered as self-report or, when parents are married and cohabiting, as one parent reporting on the behavior of another parent.

\section{References}

Aiken, L. S., \& West, S. G. (1991). Multiple regression: Testing and interpreting interactions. Newbury Park: Sage.

Archer, J. (1999). Assessment of the reliability of the Conflict Tactics Scales: A meta-analytic review. Journal of Interpersonal Violence, 14(12), $1263-1289$.

Arias, I., \& Beach, S. R. H. (1987). Validity of self-reports of marital violence. Journal of Family Violence, 2(2), 139-149.

Bates, J. E., \& Bayles, K. (1984). Objective and subjective components in mothers' perceptions of their children from age 6 months to 3 years. Merrill-Palmer Quarterly, 30, 111-130.

Bates, J. E., Freeland, C. B., \& Lounsbury, M. L. (1979). Measurement of infant difficultness. Child Development, 50, $794-803$.

Bates, J. E., Pettit, G. S., Dodge, K. A., \& Ridge, B. (1998). Interaction of temperamental resistance to control and restrictive parenting in the development of externalizing behavior. Developmental Psychology, 34, 982-995.

Bates, J. E., Schermerhorn, A. C., \& Goodnight, J. A. (2010). Temperament and personality through the life span. The handbook of life-span development John Wiley \& Sons, Inc.

Blackson, T. C., Tarter, R. E., \& Mezzich, A. C. (1996). Interaction between child temperament and parental discipline practices on behavioral adjustment in preadolescent sons of substance abuse and normal fathers. American Journal of Drug and Alcohol Abuse, 22(3), 335-348.

Coley, R. L., \& Morris, J. E. (2002). Comparing father and mother reports of father involvement among low-income minority families. Journal of Marriage and Family, 64(4), 982-998.

Cook, J. C., Schoppe-Sullivan, S. J., Buckley, C. K., \& Davis, E. F. (2009). Are some children harder to coparent than others? Children's negative emotionality and coparenting relationship quality. Journal of Family Psychology, 23, 73.

Crouter, A. C., Bumpus, M. F., Davis, K. D., \& McHale, S. M. (2005). How do parents learn about adolescents' experiences? Implications for parental knowledge and adolescent risky behavior. Child Development, 76(4), 869-882.

Crouter, A. C., Helms-Erikson, H., Updegraff, K., \& McHale, S. M. (2003). Conditions underlying parents' knowledge about children's daily lves in middle childhood: Between- and within-family comparisons. Child Development, 70(1), 246-259.

Dodge, K. A., Bates, J. E., \& Pettit, G. S. (1990). Mechanisms in the cycle of violence. Science, 1678-1683.

Edelson, J. L., \& Brygger, M. P. (1986). Gender differences in reporting of battering incidences. Family Relations, 35(3), 377-382.

Gershoff, E. T. (2002). Corporal punishment by parents and associated child behaviors and experiences: A meta-analytic and theoretical review. Psychological Bulletin, 128(4), 539-579.

Hollingshead, A. B. (1979). Four-Factor Index of Social Status. Yale University.

Jose, P. E.(2008). ModGraph-I: A programme to compute cell means for the graphical display of moderational analyses: The internet version, Version 2.0. Wellington, New Zealand: Victoria University of Wellington. Retrieved from http://www.victoria.ac.nz/psyc/staff/paul-jose-files/modgraph/modgraph.php

Lee, S. J., Altschul, I., Shair, S. R., \& Taylor, C. A. (2011). Hispanic fathers and risk for maltreatment in father-involved families of young children. Journal of the Society for Social Work and Research, 2, 125-142.

Lee, S. J., Guterman, N. B., \& Lee, Y. (2008). Risk factors for paternal physical child abuse. Child Abuse Er Neglect, 32, 846-858.

Mammen, K. (2011). Fathers' time investments in children: Do sons get more? Journal of Population Economics, $24,839-871$.

McBride, B. A., Schoppe, S. J., \& Rane, T. R. (2002). Child characteristics, parenting, stress, and parental involvement: Fathers versus mothers. Journal of Marriage and Family, 64, 998-1011.

Mikelson, K. S. (2008). He said, she said: Comparing mother and father reports of father involvement. Journal of Marriage and Family, $70,613-624$.

Raley, S., \& Bianchi, S. (2006). Sons, daughters, and family process: Does gender of children matter? Annual Review of Sociology, $32,401-421$.

Runyan, D. K., Cox, C. E., Dubowitz, H., Newton, R. R., Upadhyaya, M., Kotch, J. B., Leeb, R. T., Everson, M. D., \& Knight, E. D. (2005). Describing maltreatment: Do child protective service reports and research definitions agree? Child Abuse E Neglect, 29(5), 461-477.

Schafer, J. (1996). Measuring spousal violence with the Conflict Tactics Scale: Notes on reliability and validity issues. Journal of Interpersonal Violence, 11(4), $572-585$.

Simpson, L. E., \& Christensen, A. (2005). Spousal agreement regarding relationship aggression on the Conflict Tactics Scale-2. Psychological Assessment, 17(4), 423-432.

Straus, M. A. (1979). Measuring intrafamily conflict and violence: The Conflict Tactics (CT) Scales. Journal of Marriage and the Family, 41, 75-88.

Straus, M. A. (2001). New evidence for the benefits of never spanking. Society, 38(6), 52-60.

Straus, M. A. (2004). Scoring the CTS2 and CTSPC. Durham, NH: Family Research Laboratory, University of New Hampshire.

Straus, M. A., \& Field, C. (2003). Psychological aggression by American parents: National data on prevalence, chronicity, and severity. Journal of Marriage and Family, 65, 795-808.

Straus, M. A., \& Hamby, S. L. (1997). Measuring physical and psychological maltreatment of children with the Conflict Tactics Scales. In G. K. <ED> Kantor, \& J. L. <ED> Jasinski (Eds.), Out of the darkness: Perspectives on family violence (pp. 119-135). Thousand Oaks: Sage.

Straus, M. A., Hamby, S. L., Finkelhor, D. W., Moore, D. W., \& Runyan, D. (1998). Identification of child maltreatment with the Parent-Child Conflict Tactics Scales: Development and psychometric data for a national sample of American parents. Child Abuse E' Neglect, 22, 249-270.

Straus, M. A., \& Stewart, J. H. (1999). Corporal punishment by American parents: National data on prevalence, chronicity, severity, and duration, in relation to child and family characteristics. Clinical Child and Family Psychology Review, 2, 55-70.

Taylor, C. A., Lee, S. J., Guterman, N. B., \& Rice, J. (2010). Use of spanking for 3 year-old children and associated intimate partner aggression or violence. Pediatrics, 126(3), 415-424.

Taylor, C. A., Manganello, J. A., Lee, S. J., \& Rice, J. (2010). Maternal spanking of 3-year-old children and subsequent risk of children's aggressive behavior. Pediatrics, 126(5), e1057-e1065.

Updegraff, K. A., McHale, S. M., Crouter, A. C., \& Kupanoff, K. (2001). Parents' involvement in adolescents' peer relationships: A comparison of mothers' and fathers' roles. Journal of Marriage and Family, 63, 655-668.

Vega, E. M., \& O'Leary, K. D. (2007). Test-retest reliability of the Revised Conflict Tactics Scales (CTS2). Journal of Family Violence, 22, 703-708.

Weiss, B., Dodge, K. A., Bates, J. E., \& Pettit, G. S. (1992). Some consequences of early harsh discipline: Child aggression and a maladaptive social information processing style. Child Development, 63(6), 1321-1335.

Yeung, W. J., Sandberg, J. F., Davis-Kean, P. E., \& Hofferth, S. L. (2001). Children's time with fathers in intact families. Journal of Marriage and Family, 63, 136-154. 